\title{
Serosal surfaces, mucin pools, and deposits, Oh my: challenges in staging colorectal carcinoma
}

\author{
Wendy L Frankel and Ming Jin \\ Department of Pathology, The Ohio State University Wexner Medical Center, Columbus, OH, USA
}

\begin{abstract}
Colorectal carcinoma is the third most common cancer in the United States. Proper and standardized pathologic staging is vital for prognostic assessment and impacts therapeutic decisions. The Tumor Node Metastasis (TNM) staging system was developed by the American Joint Committee on Cancer (AJCC) to be a data-driven, evidence-based staging system providing an accurate prediction of outcome. The AJCC 7th edition (2010) included several changes clarifying some issues and leading to new controversies. We aim to address selected challenging issues in tumor T staging, neoadjuvant treatment effects in rectal cancer, and definition of lymph node vs tumor deposit. Serosal involvement in colorectal cancer is staged as T4, which is associated with decreased survival and may impact additional therapy decisions. Although careful sampling and sectioning are helpful, challenges remain in interpretation of tumor within $1 \mathrm{~mm}$ of serosal surface with a reaction. Elastic stain as a surrogate marker for serosal invasion has been studied, but its usefulness remains unclear. Some unique issues in rectal cancer include the presence of serosa in proximal but not in distal tumors and post-neoadjuvant effects. Tumor should be staged based on tumor cells rather than acellular mucin pools. Additionally, tumor response should be graded only in primary tumor but not in lymph nodes or metastatic sites. The distinction between tumor deposits and lymph nodes has been modified in AJCC TNM from using size in the 5th edition, to the round contour in the 6th edition, to only features of residual lymph node architecture in the 7th edition. Interobserver variability remains but tumor deposits should be documented when present. The number of deposits should not be added to the total number of positive lymph nodes, and the N1c designation should only be used in cases without any positive lymph nodes. Future clarification will likely evolve as more data become available.

Modern Pathology (2015) 28, S95-S108; doi:10.1038/modpathol.2014.128
\end{abstract}

Colorectal carcinoma (CRC) is the third most common cancer in the United States. ${ }^{1,2}$ According to National Cancer Institution Surveillance, Epidemiology, and End Results Program (SEER) Stat Fact Sheets, it is estimated that there will be $\sim 140000$ new cases and greater than 50000 deaths in 2014 in the United States. Pathologic assessment is the gold standard for determining local extent of disease, and is vital for prognosis and decisions regarding need for adjuvant therapy and entrance to clinical trials. The strongest predictor of survival is pathologic staging. Other important morphologic prognostic factors include tumor type and margin

Correspondence: Dr WL Frankel, MD, Department of Pathology, Ohio State University, E411 Doan Hall, 410 West 10th Avenue, Columbus, $\mathrm{OH} 43210$, USA.

E-mail: wendy.frankel@osumc.edu

Received 14 June 2014; revised 11 July 2014; accepted 12 July 2014 assessment. Stage-independent factors include lymphvascular and perineural invasion, tumor border configuration, tumor budding, host lymphoid response, and morphologic features suggestive of microsatellite instability. ${ }^{3}$

A number of challenges and caveats exist in the pathologic staging and reporting of CRC. ${ }^{4,5}$ In this article, we focus on selected issues in tumor $\mathrm{T}$ staging, neoadjuvant treatment effects in rectal cancer, and the definition of lymph node vs tumor deposits. The Tumor Node Metastasis (TNM) staging system was developed by the American Joint Committee on Cancer (AJCC) to be a data-driven, evidence-based cancer staging system providing an accurate prediction of outcome. As new evidence is acquired, frequent updating of staging is essential. The AJCC Cancer Staging Manual 7th edition, released in 2010, included several changes clarifying some issues and leading to new controversies. ${ }^{3}$ The College of American Pathologists (CAP) 
Table 1 Colorectal cancer $\mathrm{T}$ staging summary (modified from AJCC 7th edition)

\begin{tabular}{ll}
\hline T staging & Description/depth of tumor invasion \\
\hline Tx & Primary tumor cannot be assessed \\
T0 & $\begin{array}{l}\text { No evidence of primary tumor } \\
\text { Tis }\end{array}$ \\
lamina is intraepithelial or invades \\
T1 & Tumor invades submucosa \\
T2 & Tumor invades muscularis propria \\
T3 & Tumor invades beyond muscularis propria \\
T4a & Tumor penetrates to the surface of the visceral \\
& peritoneum \\
T4b & Tumor directly invades or is adherent \\
& to adjacent organs/structures
\end{tabular}

checklist was recently updated at the CAP website in October 2013.

\section{Tumor T staging}

The T category of the TNM staging system is divided into Tis, T1, T2, T3, and T4 depending on depth of tumor invasion and extension into adjacent organs/ structures (Table 1). Tis is tumor limited to the muscularis mucosa, T1 lesions are limited the submucosa, T2 lesions are limited to the muscularis propria, T3 lesions extend beyond the muscularis propria into the pericolonic adipose tissue, and $\mathrm{T} 4$ lesions penetrate the serosa and/or extend into adjacent organs/structures. T3 tumors in some studies have been subdivided, but this subdivision has not been accepted in the United States or AJCC Cancer staging manual. T4 tumors are divided into T4a and T4b.

\section{Serosal Involvement}

One of the most controversial areas in $\mathrm{T}$ staging is the distinction between deep T3 and T4a tumors. This distinction is not only important for helping to predict prognosis, but is also vital for some treatment decisions. Patients with Stage II tumors (lymph node negative) do not typically get treated with adjuvant chemotherapy, while patients with Stage III and IV tumors do. It has been suggested by the American Society of Clinical Oncology (ASCO) that the routine use of adjuvant chemotherapy is not recommended for patients with Stage II colon cancer, but there are some patient populations to consider for adjuvant chemotherapy, such as those with inadequately sampled nodes, T4 tumors, bowel perforation, or poorly differentiated histology. ${ }^{6}$ The National Comprehensive Cancer Network (NCCN) Guidelines (Version 2.2014) characterize high-risk factors for systemic recurrence as poorly differentiated histology (not MSI-H), lymphatic/vascular invasion, perineural invasion, $<12$ lymph nodes identified in colon cancer, bowel obstruction, localized perforation, and close, indeterminate or positive margins. Therefore, a patient with a pT3No cancer will likely not get adjuvant chemotherapy, while a patient with pT4No cancer may be treated with adjuvant chemotherapy.

There has been significant variability in reporting serosal involvement. ${ }^{7-9}$ Studies with meticulous sampling including multiple sections of tumor and step sections in most concerning areas have shown high rate $(59 \%)$ of serosal involvement. Other studies have shown much lower rates of involvement. In a study by Shepherd et $a l^{8}$ with meticulous sampling of 412 colon cancers, histological assessment of local peritoneal involvement was described as follow: tumor well clear of closest peritoneal surface (LP1, 20\%); mesothelial inflammatory and/or hyperplastic reaction with tumor close to, but not at the peritoneal surface (LP2, $22 \%$ ); tumor present at the peritoneal surface with inflammatory reaction, mesothelial hyperplasia, and/or ulceration (LP3, 27\%); and tumor cells shown free in peritoneum and evidence of adjacent ulceration (LP4, 32\%). The results from Shepherd's group ${ }^{8,9}$ and a recent study ${ }^{10}$ suggested that peritoneal involvement is the parameter with the strongest independent prognostic significance and is even more powerful than the extent of local spread or lymph node involvement. Serosal involvement is thought to be underdiagnosed in up to $20 \%$ of cases called T3 rather than T4a, likely due to inadequate sampling and not recognizing serosal penetration. Step sections or more sampling can be helpful in some cases. Histological parameters to identify these features are not always entirely straightforward and the absence of standard guidelines for assessing peritoneal involvement is felt to likely contribute to underdiagnosis. ${ }^{11}$ If tumor is seen close to the surface, then we evaluate deeper levels and may regross the tumor to take more sections before classifying as T4 (Figure 1a-d). Also, serosal clefts may contain tumor cells and are important to evaluate (Figure 1e and f).

The following findings are suggested by CAP to be considered to represent serosal involvement by tumor and are associated with decreased survival: tumor present at the serosal surface with inflammatory reaction, mesothelial hyperplasia, and/or erosion/ulceration; and free tumor cells on the serosal surface (in the peritoneum) with underlying ulceration of the visceral peritoneum. A mesothelial inflammatory and/or hyperplastic reaction with tumor close to, but not at, the serosal surface is currently not included in CAP protocol. This type of local peritoneal reaction remains controversial. A recent study by Panarelli et a $1^{12}$ using serosal scrape cytology in 128 cases of colon cancer showed that peritoneal cytology was positive in 19\% T3 (46\% in T3 within $1 \mathrm{~mm}$ of serosal reaction) and 55\% T4 tumors. Additionally, when tumor was within $1 \mathrm{~mm}$ of the serosal surface, frequent reactive findings 


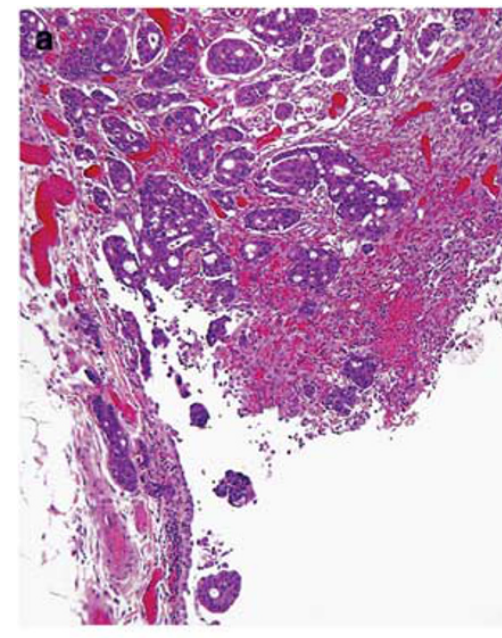

C
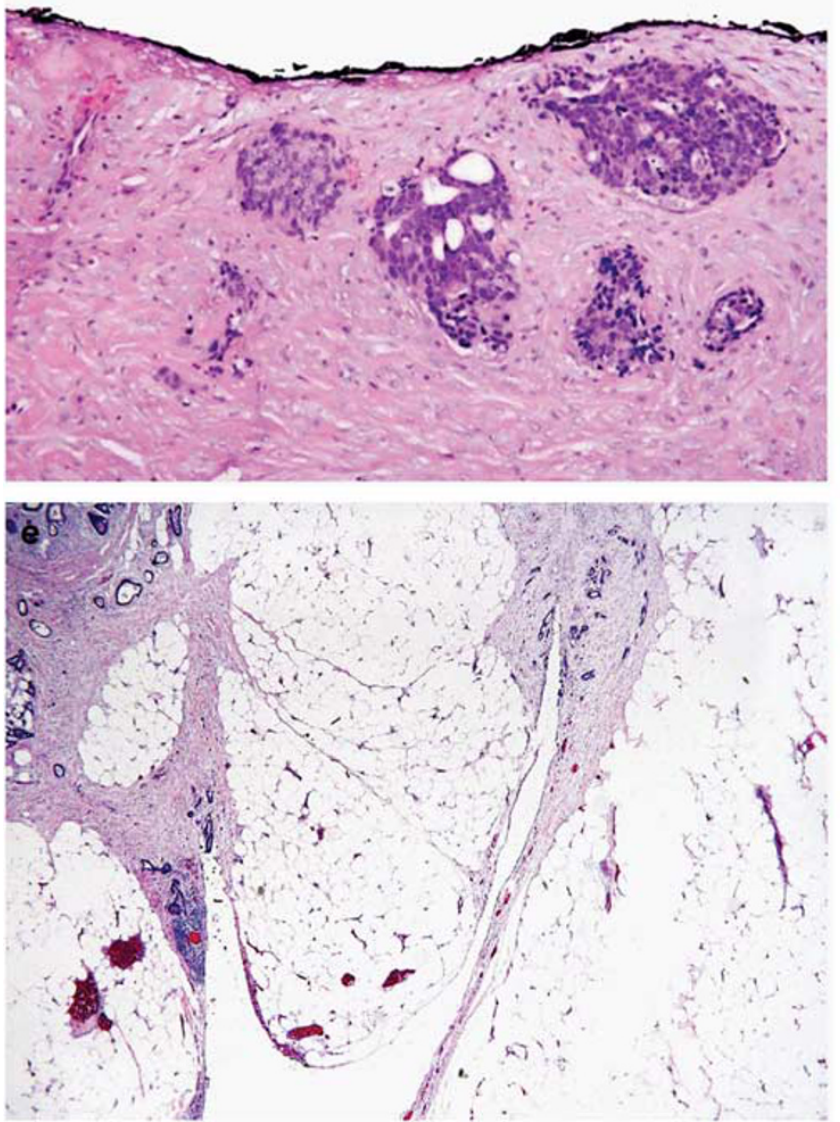

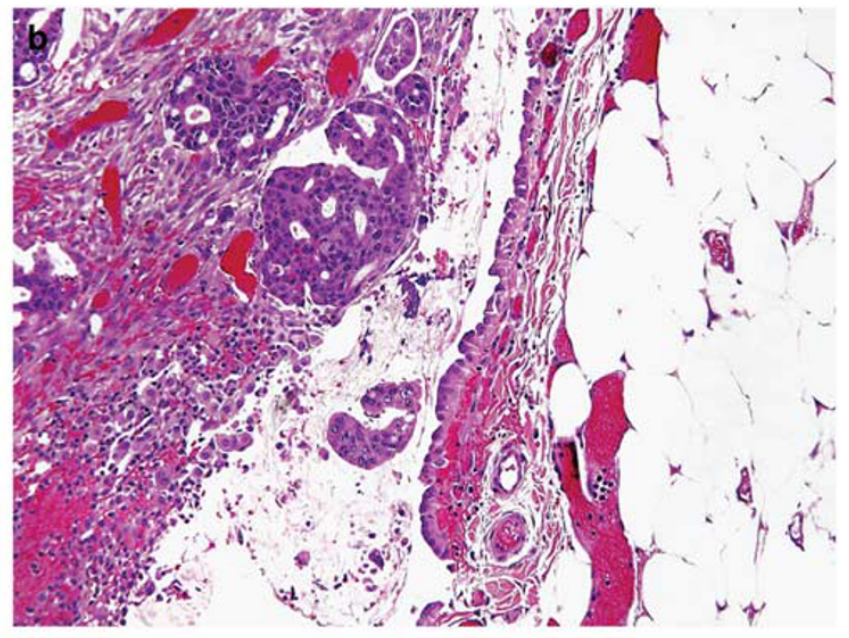

d
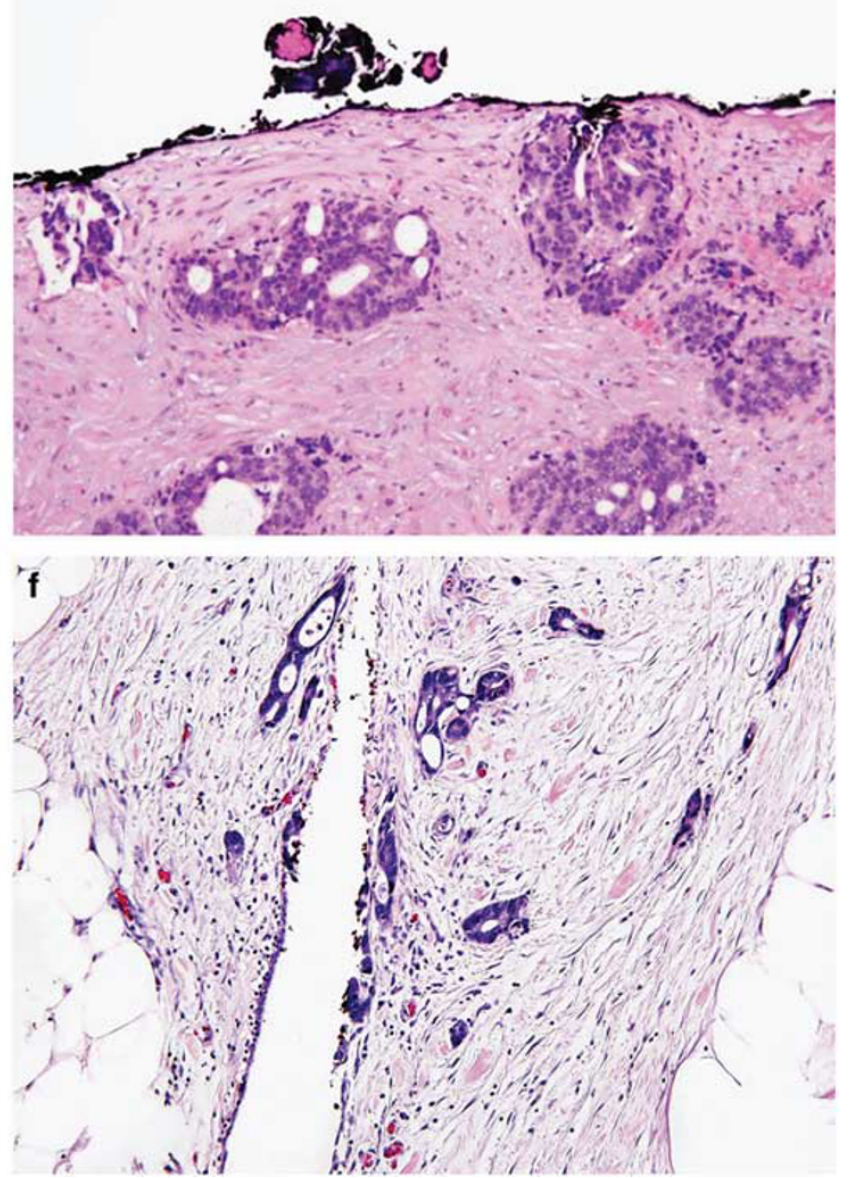

Figure 1 T4a tumors (H\&E stain). (a, b) A straightforward T4a $(\mathbf{a}, \times 40 ; \mathbf{b}, \times 100)$ with tumor cells on the serosal surface is shown. (c, d) A different case of T4a is shown: initial level $(\mathbf{c}, \times 100)$ shows the tumor cells close to but not at the serosal surface; deeper level $(\mathbf{d}, \times 100)$ shows the tumor cells on the serosal surface, and thus should be classified as T4a. (e, f) Serosal clefts that contain tumor cells and are important to evaluate $(\mathbf{e}, \times 20 ; \mathbf{f}, \times 100)$ are shown.

were observed that suggested peritoneal involvement such as fibroinflammatory or granulation tissue, peritumoral abscess that communicated to the surface, hemorrhage, fibrin, and/or reactive mesothelial cells. Therefore, it was suggested that cancer cases with tumor less than $1 \mathrm{~mm}$ from the serosal surface may be better classified as T4. This remains controversial. Another recent study by Snaebjornsson et a ${ }^{10}$ concluded that only Shepherd's LPI4 and a subgroup of LPI3 (borderline 
LPI3/LPI4) but not LPI2 (reaction with tumor close to, but not at the peritoneal surface) should be considered T4a. Figure 2 shows challenging cases of tumor with associated fibroinflammatory reaction and peritumoral abscess close to but not at serosal surface.

Since mesothelial cells can be inconspicuous in routine hematoxylin and eosin (H\&E) stain, ancillary stains such as the cytokeratin 7 immunohistochemical stain have been considered to help to recognize mesothelial cells (Figure 3). However, Liang et al demonstrated that cytokeratin 7 only highlighted mesothelial cells in 27 of 168 colorectal cancer cases tested, and only helped the identification of serosal invasion in 5 cases $(3 \%) .{ }^{3}$ They thus suggested that cytokeratin 7 was not very useful in this purpose.

\section{Elastic Stain to Identify Elastic Lamina Invasion}

Since the distinction between T3 and T4a tumors can be challenging by histology alone, the elastic stain has been investigated to assess invasion of the elastic lamina as a surrogate for serosal surface invasion. ${ }^{13-16}$ The elastic stain is useful in assessing involvement of the visceral peritoneum in lung cancers, and is used in AJCC TNM 7th edition to help stage lung cancers. The subserosal elastic lamina is located just deep to the peritoneum in the colon. Studies have varied in terms of the stain used and number of sections stained (Table 2). Grin et $a l^{14}$ recently evaluated 217 cases and found that disease-free survival was not significantly different between T3 tumors with and without elastic lamina invasion. Furthermore, they found that disease-free survival was significantly shorter in patients with T4 tumors than those with T3 with or without invasion of the elastic lamina. Additionally, only $28 \%$ of cases showed strong and continuous staining of the elastic lamina. In contrast, three other studies have shown that survival was significantly shorter in those with elastic lamina invasion than those without invasion, ${ }^{13,15,16}$ and two of these reported survival in some subsets of cases more similar to T4 lesions than T3 without
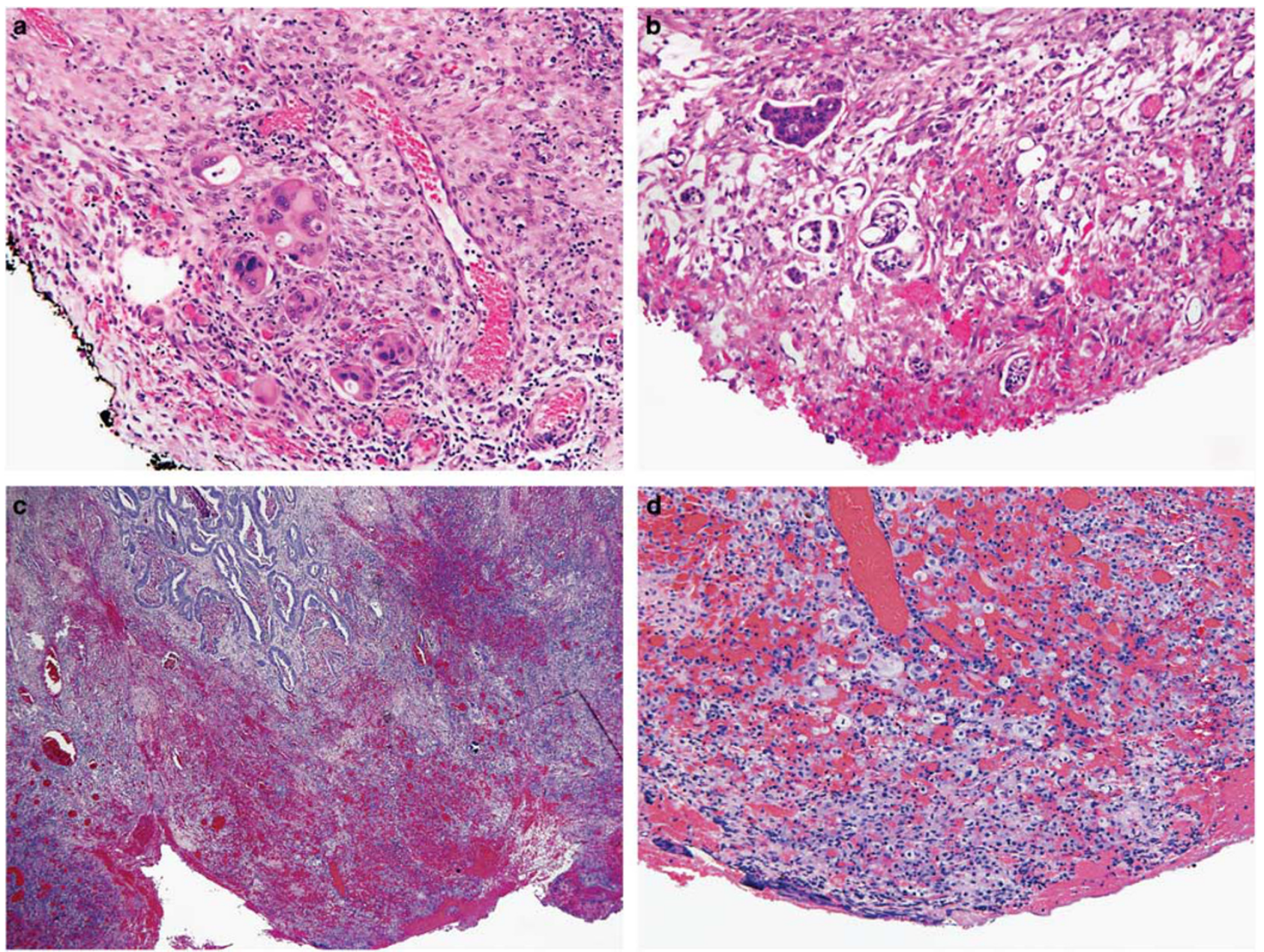

Figure 2 Challenging cases of tumors that are either deep T3 or T4a with associated reaction (H\&E stain). (a, b) Tumor and associated fibroinflammatory reaction $(\mathbf{a}, \times 100 ; \mathbf{b}, \times 200)$ is shown. $(\mathbf{c}, \mathbf{d})$ Tumor and associated peritumoral abscess is shown. No gross perforation is identified, but there is exuberant acute inflammation with no tumor cells at or within $1 \mathrm{~cm}$ of the serosal surface $(\mathbf{c}, \times 20$; $\mathbf{d}, \times 100)$. 

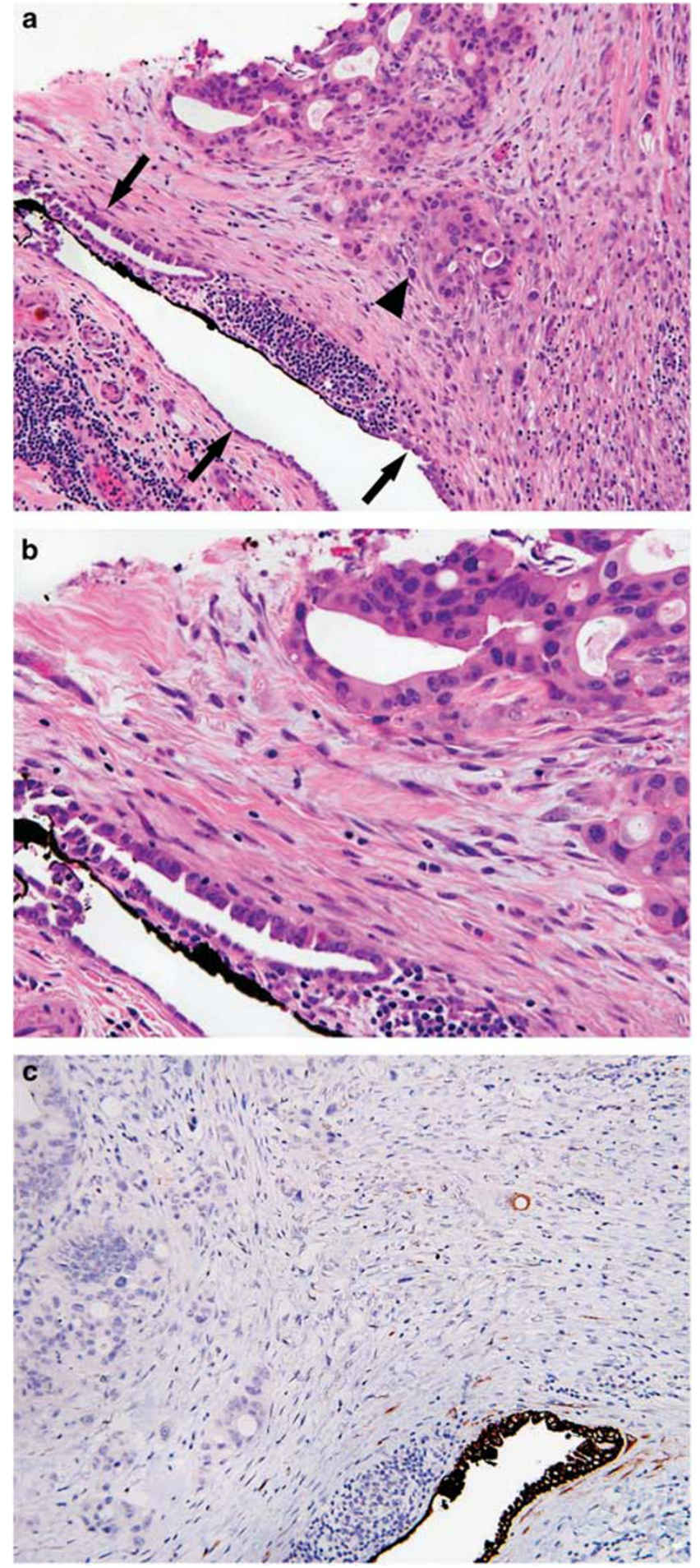

Figure 3 The utility of cytokeratin 7 stain in serosal invasion. (a, b) H\&E stain of the serosal lining mesothelial cells (arrow) and the tumor cells (arrow head) close to the surface $(\mathbf{a}, \times 100 ; \mathbf{b}, \times 200)$ is shown. (c) Cytokeratin 7 stain helpful to highlight mesothelial cells in some cases $(\times 100)$ is shown.

elastic lamina invasion. However, in Liang's study, the elastic lamina was only evaluable in $41 \%$ of cases. ${ }^{13}$ They concluded that this did not seem to be a major problem because prognosis was similar in those with no elastic lamina identified to those without elastic lamina invasion. Kojima et $a l^{15}$ stained an average of 4.6 slides per case in order to be able to interpret almost all cases (10, T4 cases could not be evaluated for elastic lamina invasion) while Liang et $a l^{13}$ only stained 1 slide per case.

Many questions remain for using elastic stain to identify elastic lamina invasion in colon cancer. ${ }^{17-19}$ In some cases, clear-cut invasion by tumor cells can be identified (Figures 4a and b). The elastic lamina is not present in all cases, particularly in the right colon, and can be difficult to interpret in some cases $^{14}$ (Figures 4c and d). It is frequently incomplete or retracted toward tumor in cases with a reaction where its use may be most necessary. Also, the use of the stain is not practical if it is necessary to stain greater than one slide for adequate interpretation. Additionally, data are not conclusive as to how to report results (upstage or add comment) if you find elastic lamina invasion in a deep T3 tumor. The use of elastic stains or other surrogate markers for serosal invasion is not currently recommended in the AJCC 7th edition. Our experience is that deeper sections are more often useful than using this surrogate marker (Figure 5).

\section{T4 Subdivisions}

$\mathrm{T} 4$ tumors are currently divided into $\mathrm{T} 4 \mathrm{a}$ and $\mathrm{T} 4 \mathrm{~b}$ lesions. Previously, studies suggested that serosal involvement was associated with a worse outcome than direct invasion of adjacent organs..$^{8,20,21}$ Therefore, AJCC TNM 6th edition supplement categorized T4a as invasion of adjacent organs and $\mathrm{T} 4 \mathrm{~b}$ as invasion of the serosa. ${ }^{22}$ Recently, a larger study showed that penetration of the visceral peritoneum had a better 5-year survival than local invasion into adjacent organs. ${ }^{23}$ AJCC TNM 7th edition now categorizes T4a as serosal involvement and $\mathrm{T} 4 \mathrm{~b}$ as local invasion of adjacent organs or structures. ${ }^{3}$ To classify a tumor as T4b, adhesion to an adjacent structure is not sufficient; tumor cells must be seen in the adhesion. Adhesions without tumor cells should not be used to classify as T4b (Figure 6).

Staging rectal tumors can be confusing, and a common misconception is that rectal tumors can never be classified as T4a. ${ }^{24,25}$ However, in peritonealized portions of the rectum (proximal), tumor can be staged as T4a. In the distal rectum, there is no peritoneal surface, therefore, a positive radial surface would make the tumor T3 R1 (microscopic involvement) or R2 (macroscopic involvement).

\section{Neoadjuvant treatment effects in rectal cancer}

Neoadjuvant chemoradiation is typically used for advanced rectal cancers that are T3 or T4 and/or lymph node positive. Patients are treated before the 
Table 2 Elastic staining for the investigation of elastic lamina invasion and outcome

\begin{tabular}{|c|c|c|c|c|c|c|}
\hline Study, year & \# Patients and stage & Elastin stain & $\begin{array}{l}\text { \# of Slides } \\
\text { stained }\end{array}$ & $\begin{array}{l}\% \text { Non- } \\
\text { evaluable }\end{array}$ & $\begin{array}{l}\text { Elastin stain } \\
\text { results }\end{array}$ & Outcome ${ }^{\mathrm{a}}$ \\
\hline Grin, $2013^{14}$ & $\begin{array}{l}217(186 \mathrm{~T} 3 \\
\text { and } 31 \mathrm{~T} 4)\end{array}$ & $\begin{array}{l}\text { Elastic trichrome } \\
\text { or Movat } \\
\text { pentachrome }\end{array}$ & 1.5 (mean) & $\begin{array}{l}18 \% \text { (only } 28 \% \\
\text { of cases strong } \\
\text { continuous) }\end{array}$ & $\begin{array}{l}65 \% \text { EL }-; \\
17 \% \text { EL }+\end{array}$ & $\begin{array}{l}\text { DFS not sig } \\
\text { worse El }+ \text { vs El -; } \\
\text { T4 DFS sig worse } \\
\text { vs T3 }\end{array}$ \\
\hline Liang, $2013^{13}$ & 244 T3 & Elastic von Gieson & 1 & $59 \%$ & $\begin{array}{l}17 \% \text { EL }-; \\
25 \% \text { EL }+\end{array}$ & $\begin{array}{l}\text { DFS and OS sig } \\
\text { worse EL }+ \text { vs El - }\end{array}$ \\
\hline Kojima, $2010^{15}$ & $\begin{array}{c}564(455 \mathrm{~T} 3 \\
\text { and } 109 \mathrm{~T} 4 \mathrm{a})\end{array}$ & Elastica & 4.6 (mean) & $\begin{array}{c}1.8 \% \\
(10 \text { cases } \mathrm{T} 4 \mathrm{a})\end{array}$ & $\begin{array}{l}56 \% \text { EL }-; \\
44 \% \text { EL }+\end{array}$ & $\begin{array}{l}\text { OS sig worse } \\
\text { EL }+ \text { vs EL - ; } \\
\text { T3 EL + no diff } \\
\text { vs T4a }\end{array}$ \\
\hline Shinto, $2004^{16}$ & $\begin{array}{l}325 \mathrm{~T} 3 \text { (39 T2 } \\
\text { and } 113 \text { T4 for } \\
\text { outcome analysis) }\end{array}$ & $\begin{array}{l}\text { Victoria-blue } \\
\text { H\&E or Elastic } \\
\text { von Gieson }\end{array}$ & Not stated & $\begin{array}{l}\text { 'almost all cases } \\
\text { could be judged' }\end{array}$ & $\begin{array}{l}47 \% \text { EL - (shallow); } \\
53 \% \text { EL + (deep) }\end{array}$ & $\begin{array}{l}\text { RR/OS sig worse } \\
\text { EL + vs EL -; } \\
\text { T3 EL + no diff } \\
\text { vs selected T4 } \\
\text { (without metastasis) }\end{array}$ \\
\hline
\end{tabular}

Abbreviations: DFS, disease-free survival; diff, difference; EL, elastic lamina invasion; OS, overall survival; RR: recurrence rate; sig, significantly. ${ }^{\mathrm{a}}$ In Kojima 2010, results significant only in colon not in rectum.
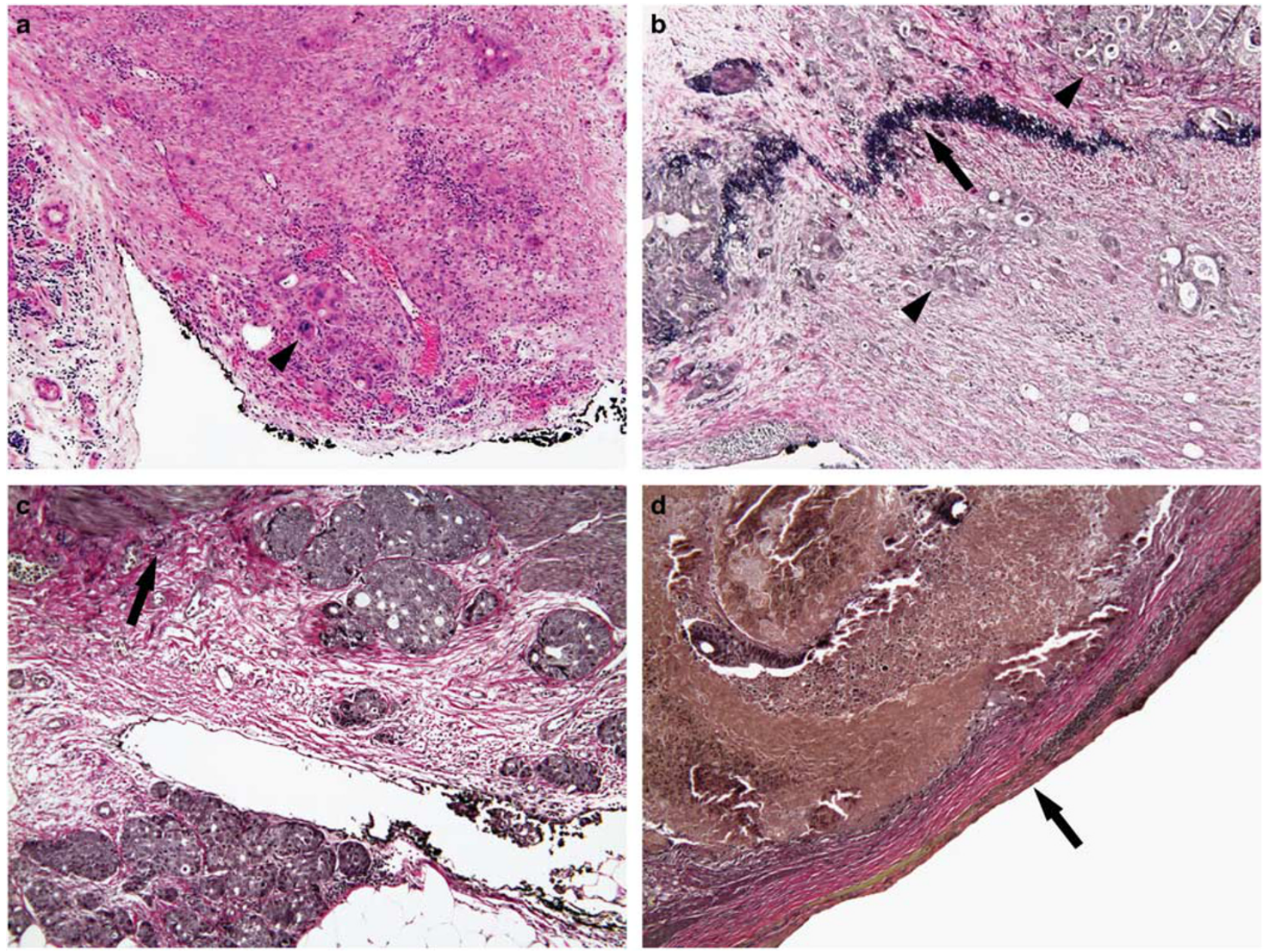

Figure 4 The use of elastic stains to evaluate elastic lamina invasion. H\&E stain shows tumor cells (arrow head) close to but not at the serosal surface $(\mathbf{a}, \times 100)$; Elastic stain shows tumor (arrow head) with elastic lamina invasion (arrow) $(\mathbf{b}, \times 100)$. However, elastic stain can be difficult to interpret $(\mathbf{c}, \times 100$; arrow points to possible elastic lamina), or incomplete (d, $\times 100$; arrow points to incomplete elastic lamina). 

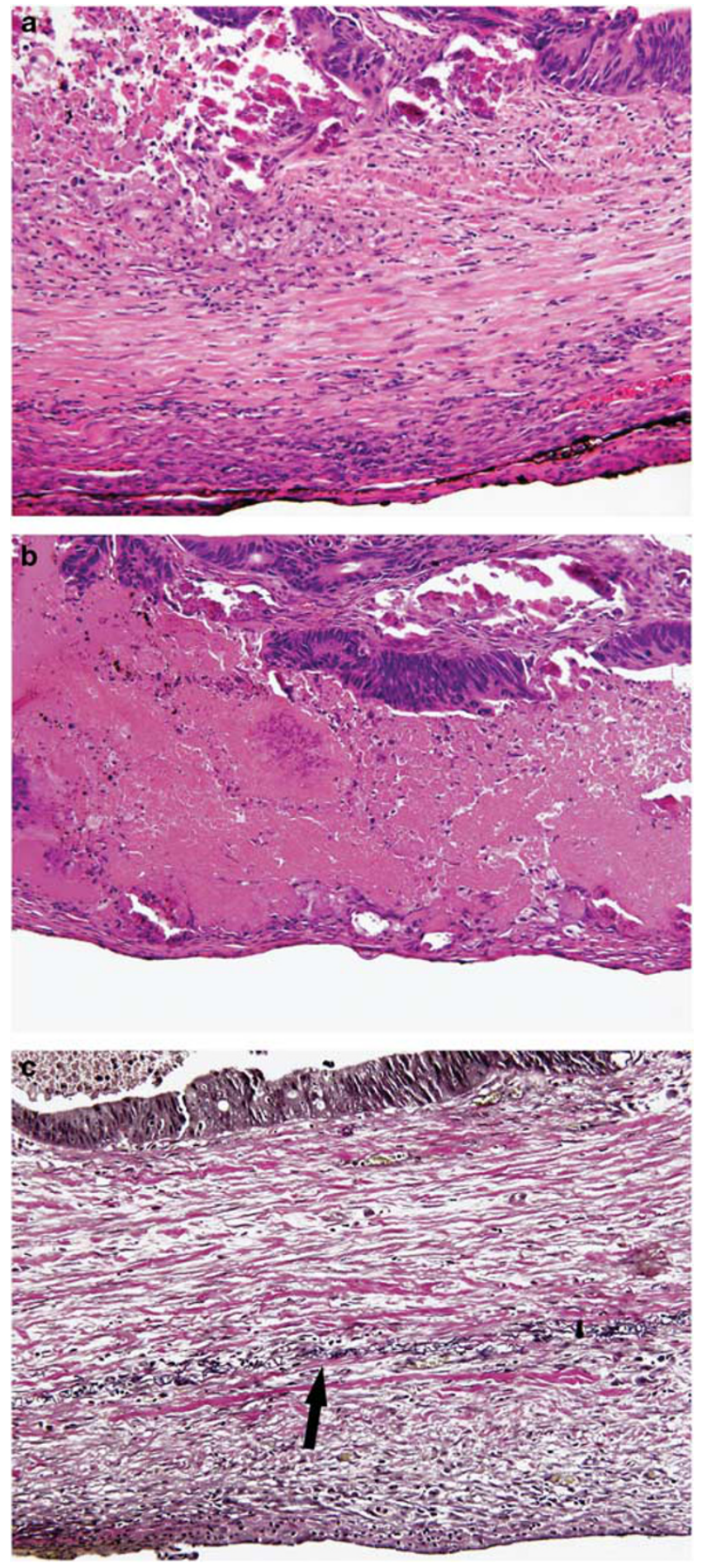

Figure 5 Deeper sections may be more useful than elastic stain in evaluating serosal involvement. H\&E section shows tumor cells are close to but not at the serosal surface $(\mathbf{a}, \times 100)$; deeper H\&E section shows tumor with necrosis on the serosal surface (T4a) (b, $\times 100$ ); while the elastic stain does not show elastic lamina invasion (c, $\times 100$, arrow points to elastic lamina).

resection, and postoperatively, all receive adjuvant chemotherapy regardless of the lymph node status after resection. The assessment of residual carcinoma is important and likely has direct bearing on prognosis. ${ }^{25,26}$ Abdul-Jalil et $a 1^{27}$ recently showed that complete response, nodal status, and circumferential resection margin but not tumor regression grade predicted long-term survival in their series of 153 rectal cancer patients.

The prefix y should be used in staging these cases. Neoadjuvant treatment effects that are commonly seen include acellular mucin pools in the rectal wall and lymph nodes and tumor regression. Acellular mucin should not be used to upstage $\mathrm{T}$ or $\mathrm{N}$ stage. In cases with mucin pools, residual carcinoma should be diagnosed only in those with residual and morphologically viable neoplastic cells within the mucin pools. Similarly, margin or lymph nodes with mucin are considered positive only when the mucin pools contain malignant cells (Figure 7). Level sections may be helpful in some cases. However, controversy remains for the definition of residual viable tumor. Shia et $a l^{5}$ suggested that a treated rectal cancer may show residual tumor cells in different stages of degeneration, and they may not be entirely equivalent to tumor cells of untreated cases. Until better definitions become available, it is recommended that the tumor cell viability can be determined based on whether the nuclear details of the cells are discernible. Tumor regression grade is determined by the evaluation of the primary tumor and not metastases in lymph nodes or other sites (Figure 8). There are several grading scales available, but interobserver agreement is overall poor. ${ }^{28}$ The pathologic response to treatment should be graded as the tumor regression grade. Table 3 shows the grading in AJCC 7 th edition. ${ }^{3}$

\section{Lymph node issues}

\section{Tumor Deposits}

Many studies have shown that tumor deposits are associated with higher tumor stage and overall poor prognosis. ${ }^{29-35}$ However, the outcome data are still complicated and confusing due to different definitions of tumor deposits. One of the most significant and controversial changes in staging CRC in the AJCC 7th edition is in the definition of tumor deposits, and the role these deposits play in staging and prognosis. In cases where no definite lymph nodal architecture remains, the distinction of a tumor deposit from involved lymph node has progressed from a reliance on size of $3 \mathrm{~mm}$ (5th edition, 1997), ${ }^{36}$ to contour (6th edition, 2002), ${ }^{22}$ to only features of residual lymph node architecture (7th edition, 2010) (Figure 9; Table 4). ${ }^{3}$ Concurrently, the role of tumor deposits in staging has moved from its prior involvement in the T category (5th/6th) to the development of a new nodal subcategory, N1c (7th). In AJCC 5th edition, tumor nodules less than $3 \mathrm{~mm}$ in size without residual lymph node were considered discontinuous extension and when necessary the T stage was upstaged. In 

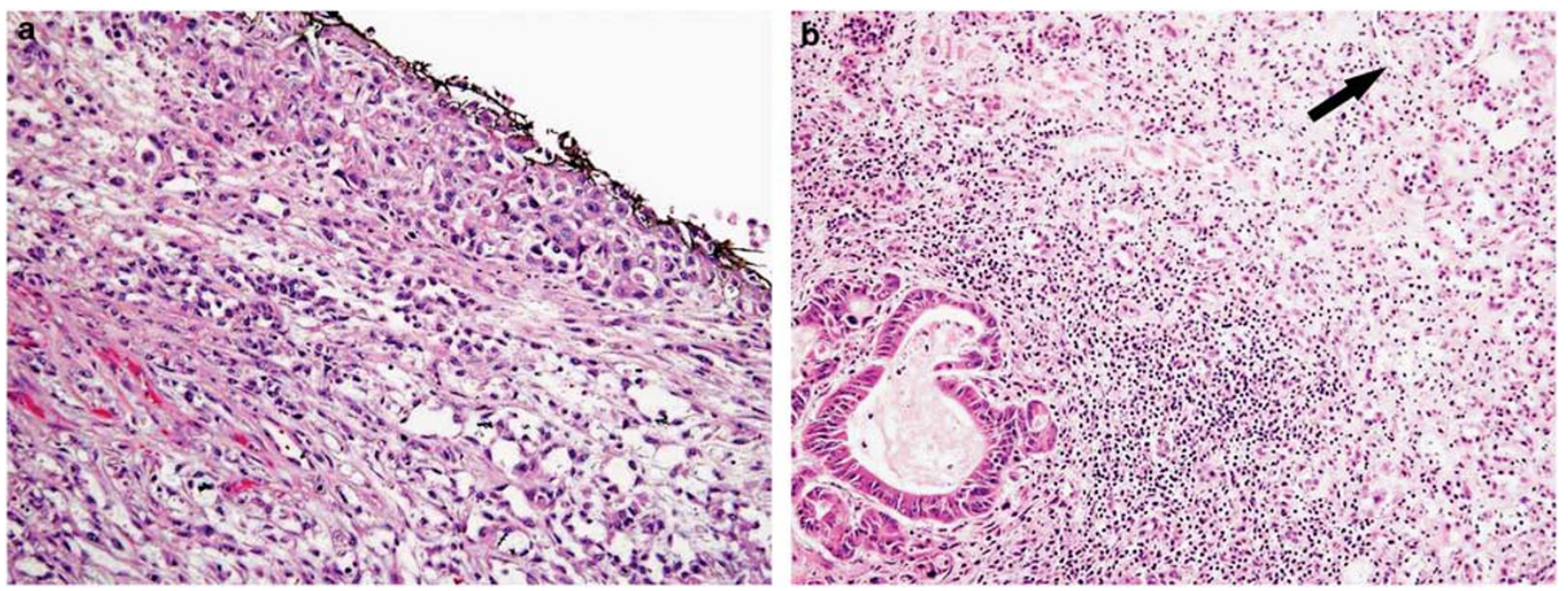

Figure 6 T4 subdivisions $(H \& E$ stain, $\times 200)$. (a) Illustrates serosal involvement by tumor, classified as T4a; (b) Illustrates local tumor invasion of adjacent organs or structures (arrow points to kidney glomeruli in the right upper corner), which is classified as T4b.
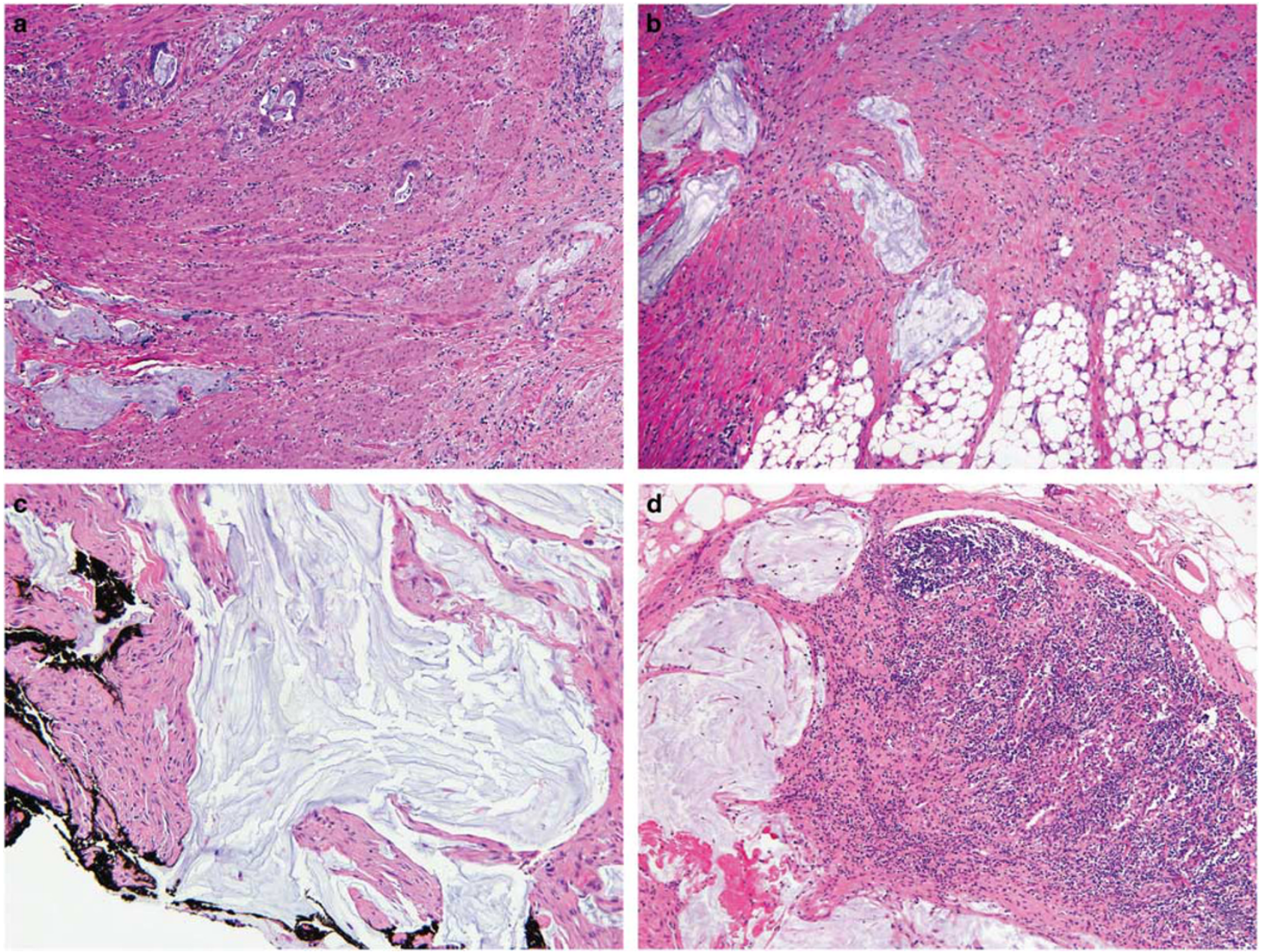

Figure 7 Acellular mucin pools in the rectal wall and lymph nodes after neoadjuvant treatment (H\&E stains). The depth of invasion and margin should be diagnosed based on the presence of residual viable neoplastic cells within the mucin pools. Even though the case shown $(\mathbf{a}, \times 20 ; \mathbf{b}, \times 40$; and $\mathbf{c}, \times 200)$ demonstrates acellular mucin pool beyond the tumor cells in the rectal wall and at the ink, the tumor is considered as yT2 and radial margin negative. Similarly, lymph node with mucin pool but no viable malignant cell is considered as negative for metastasis $(\mathbf{d}, \times 40)$. 

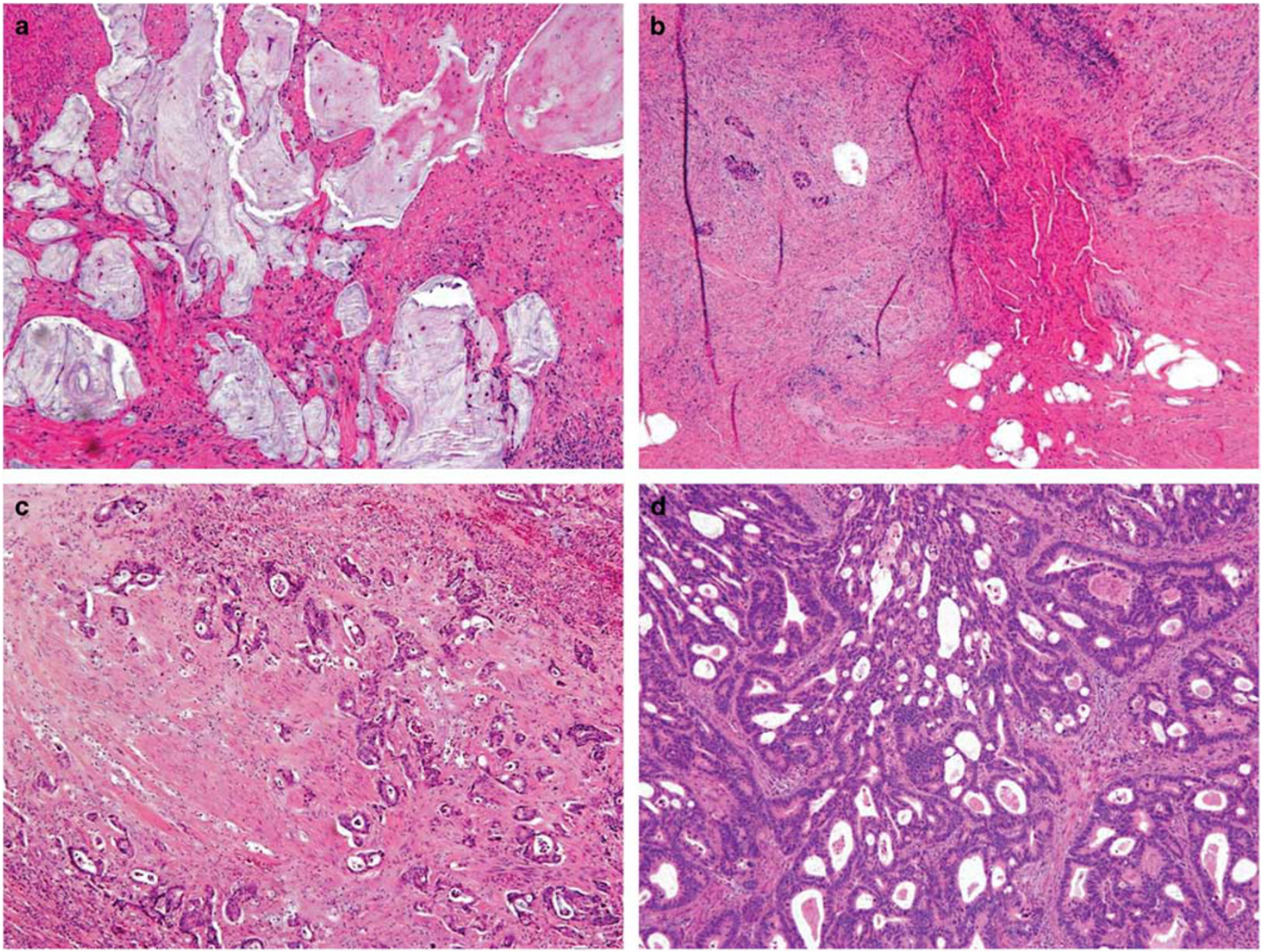

Figure 8 Images showing tumor regression grade (H\&E stain). (a) Complete response, no viable tumor cells ( $\times$ 40); (b) moderate response, occasional clusters of tumor cells $(\times 40)$; $($ c $)$ minimal response, tumor cells outgrown by fibrosis $(\times 100)$; $($ d $)$ poor response, extensive residual tumor cells $(\times 200)$.

Table 3 Tumor regression grade (pathologic response to preoperative adjuvant treatment)

\begin{tabular}{lll}
$\begin{array}{l}\text { Response } \\
\text { grade (\#) }\end{array}$ & $\begin{array}{l}\text { Response } \\
\text { grade }\end{array}$ & Response description \\
\hline 0 & $\begin{array}{l}\text { Complete } \\
\text { Moderate }\end{array}$ & $\begin{array}{l}\text { Complete absence of viable tumor cells } \\
\text { Single cells or small groups of tumor cells }\end{array}$ \\
1 & Minimal & $\begin{array}{l}\text { Residual tumor outgrown by fibrosis } \\
2\end{array}$ \\
3 & Poor & $\begin{array}{l}\text { Minimal or no tumor kill; } \\
\text { extensive residual tumor }\end{array}$ \\
& &
\end{tabular}

Modified from AJCC 7 th edition. ${ }^{3}$

AJCC 6th edition, irregular tumor nodules without residual lymph nodes were classified in the $\mathrm{T}$ category and also coded as V1 or V2.

As specified in the AJCC 7th edition, pericolonic tumor deposits are 'discrete foci of tumor found in the pericolic or perirectal fat or in adjacent mesentery (mesocolic fat) away from the leading edge of the tumor and showing no evidence of residual lymph node tissue. ${ }^{3}$ The previous size and shape criteria used for the distinction were largely arbitrary and not evidence based using outcome data. The size criterion was more objective than the contour criterion, but the outcome data were not confirmed. The new category of N1c was created to allow data collection and outcome analysis to be performed in the hopes of better understanding the clinical significance of tumor deposits. Since no definite criteria are provided to distinguish tumor deposits from totally replaced lymph nodes, the differential remains challenging in some cases where it is difficult to decide whether residual lymph node architecture exists. ${ }^{37}$ Interobserver variability remains even when evaluated by pathologists with an interest in gastrointestinal pathology. ${ }^{37}$ (Figure 10). The helpful features of residual lymph node include round shape, peripheral lymphocytes/follicles, thick capsule, and possible subcapsular sinus.

Additionally, there remains confusion with the use of the current definition and new category of N1c. It is important to remember that tumor deposits should only be diagnosed when there is no residual 


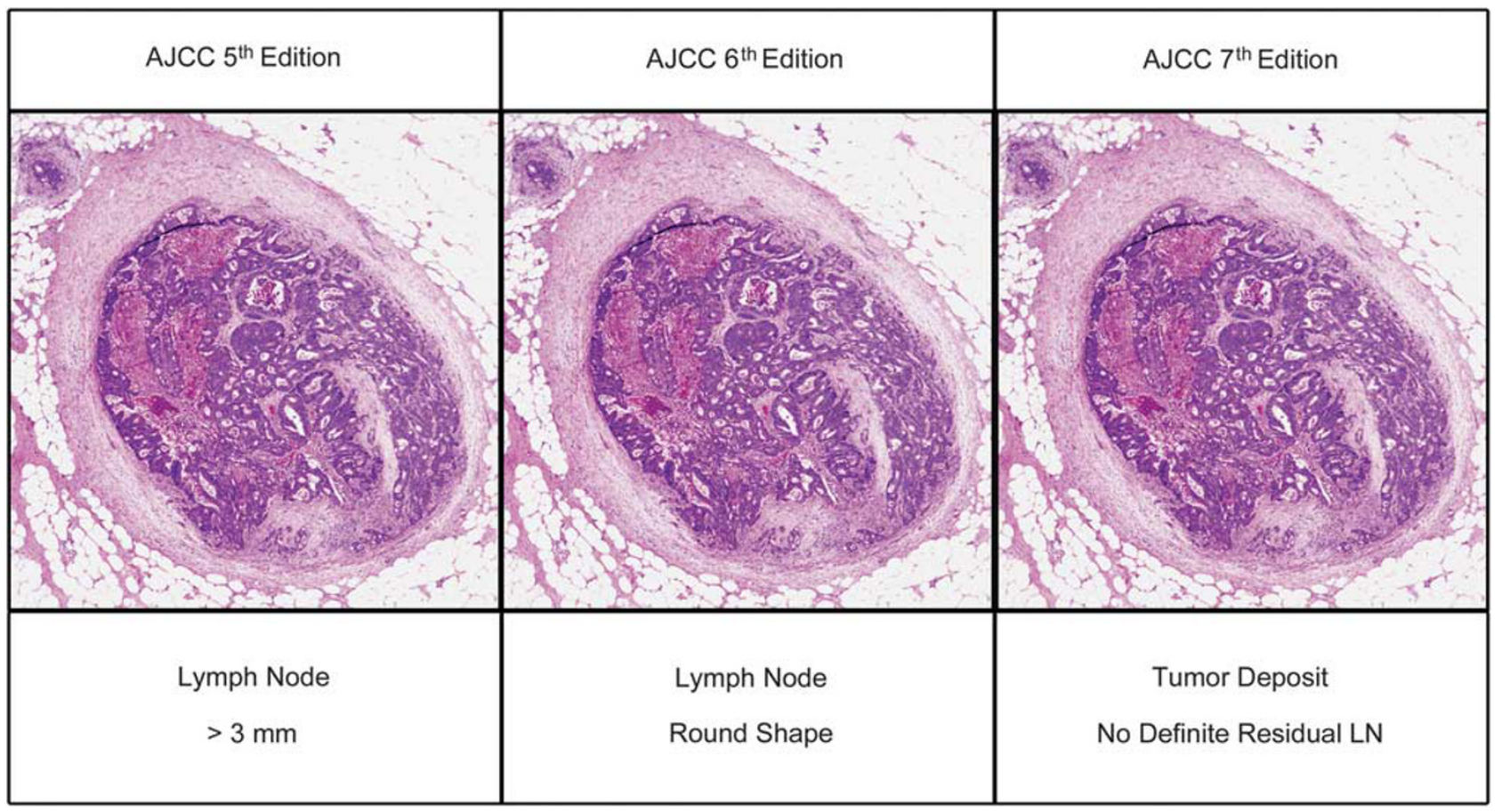

Figure 9 Definition of tumor deposits in AJCC 5th, 6th, and 7th edition (H\&E stain, $\times 40$ ). The definition has modified from reliance on size of $3 \mathrm{~mm}$ (5th edition, 1997), to contour (6th edition, 2002), and to features of residual lymph node architecture (7th edition, 2010).

Table 4 The evolution of tumor deposits

\begin{tabular}{|c|c|c|c|c|c|}
\hline AJCC edition & Year & T stage & Residual lymph node & Criteria to call lymph node & Venous invasion \\
\hline AJCC 5 th edition & 1997 & May upstage & No & $>3 \mathrm{~mm}$ & - \\
\hline AJCC 6 th edition & 2002 & May upstage & No & Round contour & $\mathrm{V} 1$ or $\mathrm{V} 2$ \\
\hline AJCC 7 th edition & 2010 & Not affected & No & - & - \\
\hline
\end{tabular}

lymph node present. If a deposit is within an identifiable blood vessel, then we do not consider the deposit a tumor deposit, but we call this area lymph-vascular invasion. To correctly stage cancers, the number of tumor deposits should be recorded separately and not added to the number of positive lymph nodes to determine the $\mathrm{N}$ stage. The category of N1c should never be used in a case with any positive lymph nodes. Tumor deposits do not change the T stage, even if the tumor is only T1 or $\mathrm{T} 2$, and the deposit is in the pericolonic adipose tissue. Additionally, N1c is not by definition worse than N1a or N1b. The use of N1c was chosen because the letter $\mathrm{c}$ was the subsequent letter in the alphabet, not necessarily to suggest prognosis.

In some cases, it is difficult to determine whether a tumor deposit near the leading edge of the tumor should be called a tumor deposit or considered discontinuous spread. Deeper sectioning can sometimes be helpful in this distinction. ${ }^{38,39}$ There is not a definite 'distance rule' for what can be considered a tumor deposit. Ueno et $a l^{34}$ studied 695 colorectal cancer patients and evaluated tumor deposits greater than or equal to $2 \mathrm{~mm}$ from the leading edge of the cancers. They found, in multivariate analysis, that the presence of tumor deposits had an adverse survival impact independent of $\mathrm{T}$ and $\mathrm{N}$ stage. Furthermore, the distance from the tumor to the deposit (if greater than $2 \mathrm{~mm}$ ) did not affect prognosis. Figure 11 shows cases where the tumor nodule is within $1 \mathrm{~mm}$ from the leading edge of the tumor. In cases where deeper sections demonstrate continuous nests of tumor (Figure 11a), the tumor nodule is best not considered as a tumor deposit. When there is no clear connection and the nodule appears discrete (Figure 11b-d), we consider the tumor nodule a tumor deposit.

\section{Required Number of Lymph Nodes}

It is clear in the literature that as many lymph nodes as possible should be evaluated to determine the $\mathrm{N}$ stage. ${ }^{40-44}$ Fat clearing does help in some cases, but is not required and is not the standard of care in most institutions. AJCC TNM 7th edition requires at 

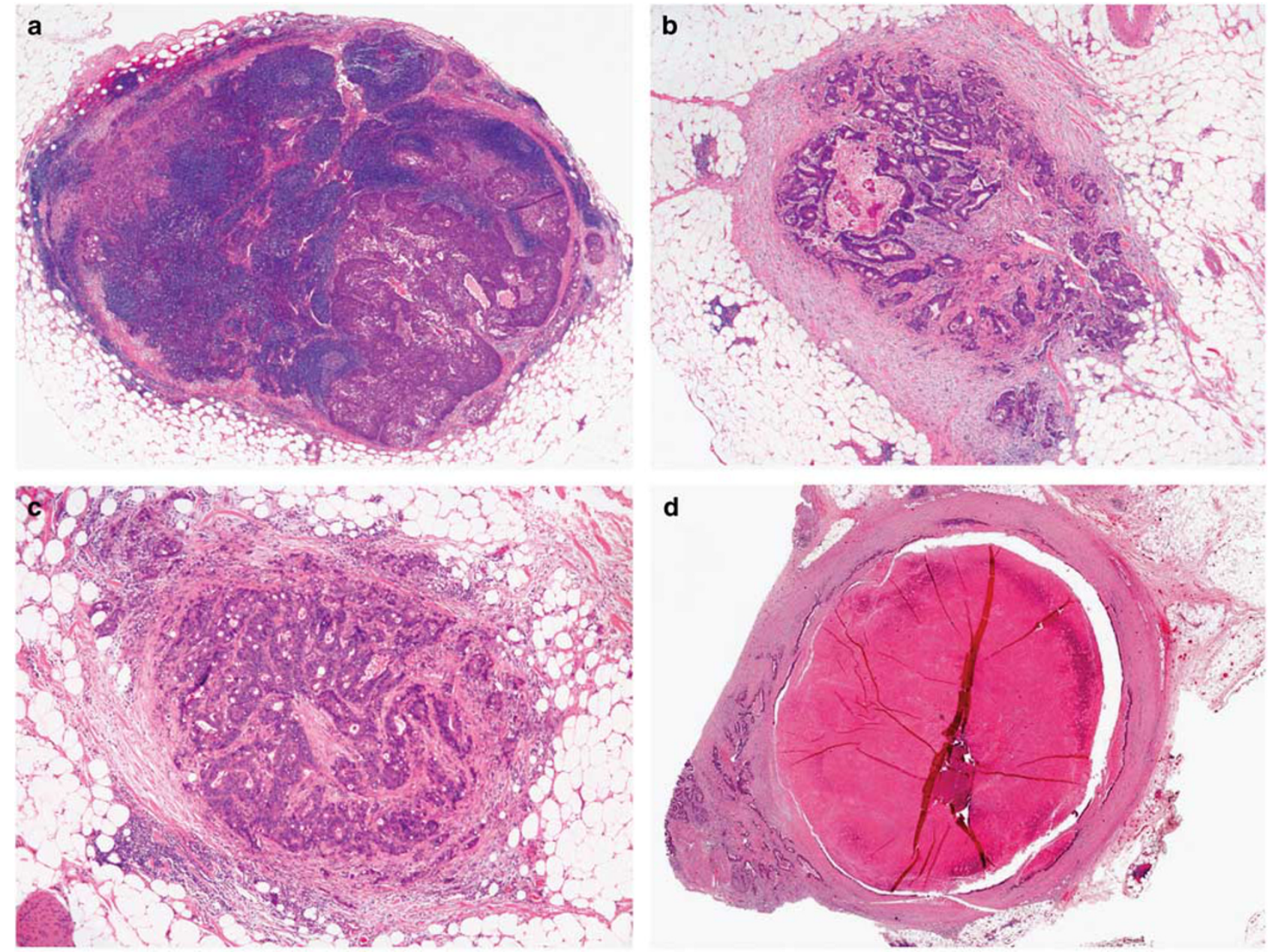

Figure 10 Tumor deposit vs lymph node metastasis (H\&E stain). (a) Clear-cut metastatic lymph node ( $\times 20)$; (b) Clear-cut tumor deposit ( $\times 20)$; (c) More difficult case with rounded contour and scattered lymphocytes at the periphery but no definitive residual lymph nodal architecture, thus is considered as tumor deposit $(\times 40)$; (d) Challenging case with rounded shape and thick capsule, difficult to classify $(\times 20)$.

least 10-14 lymph nodes in colon cancer, ${ }^{3}$ while CAP suggests regrossing when less than 12 nodes are identified. ${ }^{45,46}$ Even if less than the suggested number of lymph nodes is identified, then the tumor should still be given an $\mathrm{N}$ stage rather than designated Nx.

It has been shown that many factors affect lymph node recovery including the experience/diligence of the surgeon and grossing pathologist; patient age, gender, body habitus, immune response; and tumor site, size and length of colon resected. Additionally, the current classification of deposits that were previously called lymph nodes as tumor deposits has caused a reduction in the number of lymph nodes harvested in some cases. Several recent papers have suggested the usefulness of the lymph node ratio rather than the total number of involved lymph nodes. ${ }^{47-50}$ This is not currently recommended but is an issue that may be considered for staging in the future.
There is no minimum number of lymph nodes suggested for rectal cancer after neoadjuvant chemoradiation therapy. As many lymph nodes as possible should still be evaluated, however, it has been shown that the number of lymph nodes is reduced in these cases. ${ }^{51,52} \mathrm{~A}$ recent study by de Campos-Lobato et $a l^{45}$ concluded that the identification of less than 12 lymph nodes may be a marker of higher tumor response and decreased local recurrences. They studied 237 patients treated with neoadjuvant chemoradiation followed by total mesorectal excision and compared outcome in those with less than 12 lymph nodes with those with greater than or equal to 12 lymph nodes harvested. No significant differences were seen between the groups in overall survival, cancer-specific mortality, cancer-free survival, and distant recurrences; however, the local recurrences were significantly lower in the less than 12 lymph nodes recovered group. 

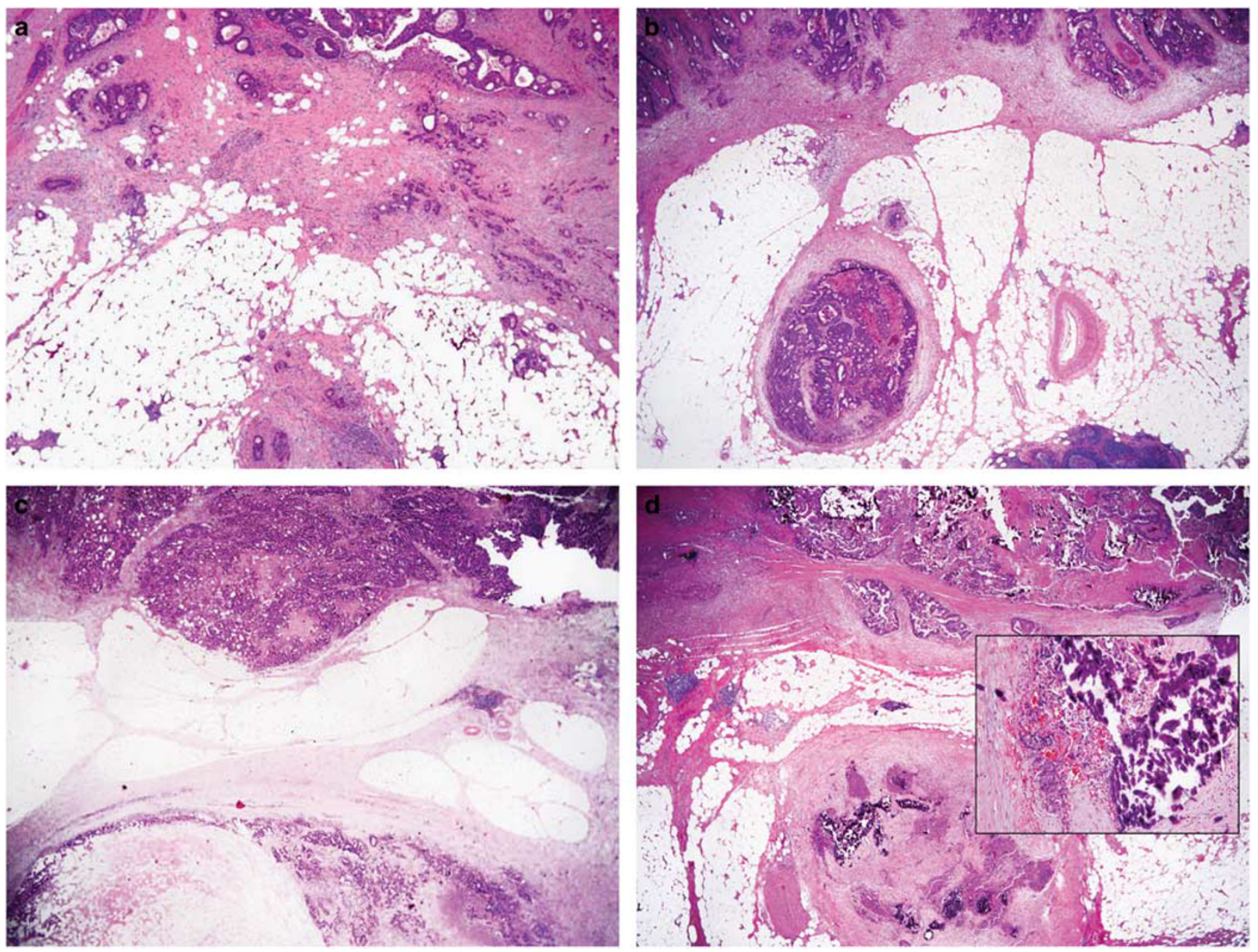

Figure 11 Cases where the tumor nodule is within $1 \mathrm{~mm}$ from the leading edge of the tumor (H\&E, $\times 40)$. Deeper sections demonstrate continuous nests of tumor (a) therefore, the tumor nodule is best not considered as a tumor deposit. When, there is no clear connection (b-d), the tumor nodule can be called a tumor deposit.

\section{Conclusions}

Proper and standardized pathologic staging is vital for prognostic assessment and impacts therapeutic decisions. There remain challenges in uniformity and definition in several areas. It is clear that serosal involvement in colon cancer is underdiagnosed, associated with decreased survival, and may impact additional therapy decisions. Although careful sampling and sectioning are helpful in some cases, challenges remain in the interpretation of surrogate markers for serosal involvement, such as tumor within $1 \mathrm{~mm}$ of the serosal surface with a reaction and invasion of the elastic lamina. Some unique issues in rectal cancer include the presence of serosa in proximal tumors and postneoadjuvant effects. It is important to remember that tumor should be staged based on viable tumor cells rather than acellular mucin pools. Additionally, tumor response should be graded only in the primary tumor and not in lymph nodes or metastatic sites. Tumor deposits remain a difficult area but should be documented when present. The number of deposits should not be added to the total number of positive lymph nodes, and the N1c designation should only be used in cases without any positive lymph nodes. AJCC 8th edition will likely address some of these issues leading to some clarification while introducing new challenges.

\section{Acknowledgments}

We acknowledge the assistance of Shawn Scully with images.

\section{Disclosure/conflict of interest}

The authors declare no conflict of interest.

\section{References}

1 Boyle P, Levin B. World Cancer Report 2008. IARC: Lyon, France, 2008.

2 Ferlay J, Shin H-R, Bray F, et al. Globocan 2008: Cancer Incidence and Mortality Worldwide. IARC: Lyon, France; 2010; IARC CancerBase No. 10 1027-5614. 
3 Edge SB, Byrd DR, Compton CC, et al. Colon and rectum. AJCC Cancer Staging Manual, 7th edn. SpringerVerlag: New York, NY, 2010;143-164.

4 Puppa G, Sonzogni A, Colombari R, et al. TNM staging system of colorectal carcinoma: a critical appraisal of challenging issues. Arch Pathol Lab Med 2010;134: 837-852.

5 Shia J, Klimstra DS, Bagci P, et al. TNM staging of colorectal carcinoma: issues and caveats. Semin Diagn Pathol 2012;29:142-153.

6 Benson AB 3rd, Schrag D, Somerfield MR, et al. American Society of Clinical Oncology recommendations on adjuvant chemotherapy for stage II colon cancer. J Clin Oncol 2004;22:3408-3419.

7 Ludeman L, Shepherd NA. Serosal involvement in gastrointestinal cancer: its assessment and significance. Histopathology 2005;47:123-131.

8 Shepherd NA, Baxter KJ, Love SB. The prognostic importance of peritoneal involvement in colonic cancer: a prospective evaluation. Gastroenterology 1997;112:1096-1102.

9 Shepherd NA, Baxter KJ, Love SB. Influence of local peritoneal involvement on pelvic recurrence and prognosis in rectal cancer. J Clin Pathol 1995;48: 849-855.

10 Snaebjornsson P, Coupe VM, Jonasson L, et al. pT4 stage II and III colon cancers carry the worst prognosis in a nationwide survival analysis. Shepherd's local peritoneal involvement revisited. Int $\mathrm{J}$ Cancer 2014;135:467-478.

11 Swamy R. Histopathological reporting of pT4 tumour stage in colorectal carcinomas: dotting the 'i's and crossing the 't's. J Clin Pathol 2010;63:110-115.

12 Panarelli NC, Schreiner AM, Brandt SM, et al. Histologic features and cytologic techniques that aid pathologic stage assessment of colonic adenocarcinoma. Am J Surg Pathol 2013;37:1252-1258.

13 Liang WY1, Chang WC, Hsu CY, et al. Retrospective evaluation of elastic stain in the assessment of serosal invasion of pT3No colorectal cancers. Am J Surg Pathol. 2013;37:1565-1570.

14 Grin A, Messenger DE, Cook M, et al. Peritoneal elastic lamina invasion: limitations in its use as a prognostic marker in stage II colorectal cancer. Hum Pathol 2013:44:2696-2705.

15 Kojima M, Nakajima K, Ishii G, et al. Peritoneal elastic laminal invasion of colorectal cancer: the diagnostic utility and clinicopathologic relationship. Am J Surg Pathol 2010;34:1351-1360.

16 Shinto E, Ueno H, Hashiguchi Y, et al. The subserosal elastic lamina: an anatomic landmark for stratifying pT3 colorectal cancer. Dis Colon Rectum 2004;47: 467-473.

17 Kojima M, Shimazaki H, Iwaya K, et al. Practical utility and objectivity: does evaluation of peritoneal elastic laminal invasion in colorectal cancer overcome these contrary problems? Am J Surg Pathol 2013;38: 144-145.

18 Kojima M, Yokota M, Saito N, et al. Elastic laminal invasion in colon cancer: diagnostic utility and histological features. Front Oncol 2012;2:179.

19 Puppa G, Shepherd NA, Sheahan K, et al. Peritoneal elastic lamina invasion in colorectal cancer: the answer to a controversial area of pathology? Am J Surg Pathol 2011;35:465-468.

20 Compton C1, Fenoglio-Preiser CM, Pettigrew N, et al. American Joint Committee on Cancer Prognostic
Factors Consensus Conference: Colorectal Working Group. Cancer 2000;88:1739-1757.

21 Keshava A, Chapuis PH, Chan C, et al. The significance of involvement of a free serosal surface for recurrence and survival following resection of clinicopathological stage B and C rectal cancer. Colorectal Dis 2007;9:609-618.

22 Greene FL, Page DL, Fleming ID, et al. Colon and rectum. AJCC Cancer Staging Manual, 6th edn. Springer-Verlag: New York, NY, 2002;113-124.

23 Gunderson LL, Jessup JM, Sargent DJ, et al. Revised TN categorization for colon cancer based on national survival outcomes data. J Clin Oncol 2010;28:264-271.

24 Gunderson LL, Jessup JM, Sargent DJ, et al. Revised tumor and node categorization for rectal cancer based on surveillance, epidemiology, and end results and rectal pooled analysis outcomes. J Clin Oncol 2010;28:256-263.

25 Moon SH, Kim DY, Park JW, et al. Can the new American Joint Committee on Cancer staging system predict survival in rectal cancer patients treated with curative surgery following preoperative chemoradiotherapy? Cancer 2012;118:4961-4968.

26 Ryan R, Gibbons D, Hyland JM, et al. Pathological response following long-course neoadjuvant chemoradiotherapy for locally advanced rectal cancer. Histopathology 2005;47:141-146.

27 Abdul-Jalil KI, Sheehan KM, Kehoe J, et al. The prognostic value of tumour regression grade following neoadjuvant chemoradiation therapy for rectal cancer. Colorectal Dis 2014;16:O16-O25.

28 Chetty R, Gill P, Govender D, et al. International study group on rectal cancer regression grading: interobserver variability with commonly used regression grading systems. Hum Pathol 2012;43:1917-1923.

29 Goldstein NS, Turner JR. Pericolonic tumor deposits in patients with $\mathrm{T} 3 \mathrm{~N}+\mathrm{MO}$ colon adenocarcinomas: markers of reduced disease free survival and intraabdominal metastases and their implications for TNM classification. Cancer 2000;88:2228-2238.

30 Gopal P, Lu P, Ayers GD, et al. Tumor deposits in rectal adenocarcinoma after neoadjuvant chemoradiation are associated with poor prognosis. Mod Pathol 2014; 27:1281-1287.

31 Nagtegaal ID, Quirke P. Colorectal tumour deposits in the mesorectum and pericolon; a critical review. Histopathology 2007;51:141-149.

32 Puppa G, Maisonneuve P, Sonzogni A, et al. Pathological assessment of pericolonic tumor deposits in advanced colonic carcinoma: relevance to prognosis and tumor staging. Mod Pathol 2007;20:843-855.

33 Puppa G, Ueno H, Kayahara M, et al. Tumor deposits are encountered in advanced colorectal cancer and other adenocarcinomas: an expanded classification with implications for colorectal cancer staging system including a unifying concept of in-transit metastases. Mod Pathol 2009;22:410-415.

34 Ueno H, Hashiguchi Y, Shimazaki H, et al. Peritumoral deposits as an adverse prognostic indicator of colorectal cancer. Am J Surg 2014;207:70-77.

35 Ueno H, Mochizuki H, Shirouzu K, et al. Multicenter study for optimal categorization of extramural tumor deposits for colorectal cancer staging. Ann Surg 2012;255:739-746.

36 Fleming ID, Cooper JS, Hensen DE, et al. Colon and rectum. AJCC Cancer Staging Manual, 5th edn. Lippincott-Raven Publishers: Philadelphia, PA, 1997;83-88. 
37 Rock JB, Washington MK, Adsay NV, et al. Debating deposits: an interobserver variability study of lymph nodes and pericolonic tumor deposits in colonic adenocarcinoma. Arch Pathol Lab Med 2014;138: 636-642.

38 Puppa G. Enhanced pathologic analysis for pericolonic tumor deposits: is it worth it? Am J Clin Pathol 2010;134:1019-1021.

39 Wunsch K, Muller J, Jahnig $\mathrm{H}$, et al. Shape is not associated with the origin of pericolonic tumor deposits. Am J Clin Pathol 2010;133:388-394.

40 Chang GJ, Rodriguez-Bigas MA, Skibber JM, et al. Lymph node evaluation and survival after curative resection of colon cancer: systematic review. J Natl Cancer Inst 2007;99:433-441.

41 Cserni G, Vinh-Hung V, Burzykowski T. Is there a minimum number of lymph nodes that should be histologically assessed for a reliable nodal staging of T3N0M0 colorectal carcinomas? J Surg Oncol 2002; 81:63-69.

42 Dillman RO, Aaron K, Heinemann FS, et al. Identification of 12 or more lymph nodes in resected colon cancer specimens as an indicator of quality performance. Cancer 2009;115:1840-1848.

43 Goldstein NS. Lymph node recoveries from 2427 pT3 colorectal resection specimens spanning 45 years: recommendations for a minimum number of recovered lymph nodes based on predictive probabilities. Am J Surg Pathol 2002;26:179-189.

44 Le Voyer TE, Sigurdson ER, Hanlon AL, et al. Colon cancer survival is associated with increasing number of lymph nodes analyzed: a secondary survey of intergroup trial INT-0089. J Clin Oncol 2003;21: 2912-2919.
45 de Campos-Lobato LF, Stocchi L, de Sousa JB, et al. Less than 12 nodes in the surgical specimen after total mesorectal excision following neoadjuvant chemoradiation: it means more than you think! Ann Surg Oncol 2013;20:3398-3406.

46 Washington MK, Berlin J, Branton P, et al. Protocol for the examination of specimens from patients with primary carcinoma of the colon and rectum. Arch Pathol Lab Med 2009;133:1539-1551.

47 Gleisner AL, Mogal H, Dodson R, et al. Nodal status, number of lymph nodes examined, and lymph node ratio: what defines prognosis after resection of colon adenocarcinoma? J Am Coll Surg 2013;217: 1090-1100.

48 Medani M, Kelly N, Samaha G, et al. An appraisal of lymph node ratio in colon and rectal cancer: not one size fits all. Int J Colorectal Dis 2013;28:1377-1384.

49 Moug SJ, Oliphant R, Balsitis M, et al. The lymph node ratio optimises staging in patients with node positive colon cancer with implications for adjuvant chemotherapy. Int J Colorectal Dis May 29:599-604.

50 Zhang J, Lv L, Ye Y, et al. Comparison of metastatic lymph node ratio staging system with the 7th AJCC system for colorectal cancer. J Cancer Res Clin Oncol 2014;139:1947-1953.

51 Govindarajan A, Gonen M, Weiser MR, et al. Challenging the feasibility and clinical significance of current guidelines on lymph node examination in rectal cancer in the era of neoadjuvant therapy. J Clin Oncol 2011;29:4568-4573.

52 Miller ED, Robb BW, Cummings OW, et al. The effects of preoperative chemoradiotherapy on lymph node sampling in rectal cancer. Dis Colon Rectum 2012;55: 1002-1007. 